\title{
Modelos tecnoassistenciais, gestão e organização do trabalho em saúde: nada é indiferente no processo de luta para a consolidação do SUS
}

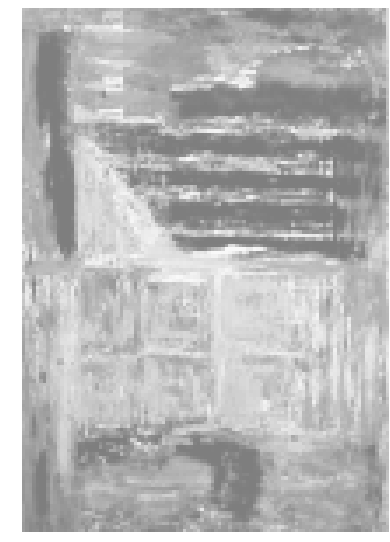

Laura Feuerwerker ${ }^{1}$

FEUERWERKER, L. M. Technical healthcare models, management and the organization of work in the healthcare field: nothing is indifferent in the struggle for the consolidation Brazil's Single Healthcare System. Interface Comunic., Saúde, Educ., v.9, n.18, p.489-506, set/dez 2005.

This article presents a critical reflection on the current situation of the development of the Brazil's Single Healthcare System (SUS - Sistema Único de Saude), by referring to the Brazilian Healthcare Reform Movement's principles, particularly as concerns the democratic commitments to the right to healthcare, the construction of the system and its policies, and the transformation of healthcare practices and of the technical care model. It analyzes the predominant ways in which care is organized, healthcare policies are designed and the challenges of healthcare work are faced. It supports the idea that democratic radicalization, enabling active and true participation of municipal administrators, workers and users in the construction of the Single Healthcare System, is indispensable for consolidating the system and healthcare as one of the rights of all citizens.

KEY WORDS: health as a right of citizens. technical healthcare model. democratization of healthcare management. policies. micro-policies of healthcare work.

O artigo propõe uma reflexão crítica sobre o momento atual de desenvolvimento da construção do Sistema único de Saúde, tendo como referência os princípios propostos pelo movimento da Reforma Sanitária Brasileira, particularmente os compromissos democráticos em relação ao direito à saúde e à construção do sistema e de suas políticas e à transformação das práticas de saúde e do modelo tecnoassistencial. São analisadas as maneiras predominantes de organização da atenção, de fazer políticas de saúde e de enfrentar os desafios do processo de trabalho em saúde. Defende-se a idéia de que uma radicalização democrática, que possibilite a participação ativa $e$ efetiva de gestores municipais, trabalhadores e usuários na construção do SUS, é indispensável para a consolidação do sistema e da saúde como direito cidadão.

PALAVRAS-CHAVE: saúde como direito do cidadão. modelo tecnoassistencial. democratização da gestão. formulação de políticas de saúde. micropolítica do trabalho em saúde.

${ }^{1}$ Pesquisadora da área de formação de profissionais de saúde; Professora Adjunta, Universidade Federal Fluminense, Rio de Janeiro. <laura.macruz@uol.com.br>

Rua Hans Staden, 10, apto 409,

Botafogo - Rio de Janeiro, RJ

22281-060 
O movimento da reforma sanitária brasileira

O Movimento da Reforma Sanitária foi ao mesmo tempo uma bandeira de luta específica e parte de uma totalidade de mudanças (Arouca, 1998), já que concretizava setorialmente (na saúde) os direitos democráticos pelos quais amplos segmentos da sociedade brasileira se mobilizavam.

Foi e segue sendo uma proposta, já que oferece princípios e proposições, como os plasmados no relatório final da VIII Conferência Nacional de Saúde, muitos dos quais incorporados ao texto constitucional. Ao mesmo tempo é um projeto, pois representa um conjunto de políticas articuladas, que incluem uma dada consciência sanitária, a defesa da participação cidadã e a vinculação da saúde com lutas políticas e sociais mais amplas. E também é um processo, pois se transformou em bandeira de lutas, possibilitou a articulação de práticas e a conformação de um projeto político-cultural consistente (Paim, 1997).

A potência do movimento da reforma sanitária no período final da ditadura e durante a Constituinte esteve baseada em sua capacidade de construir no coletivo a idéia do direito democrático de todos à saúde (uma perspectiva de igualdade numa sociedade desigual) e propor as linhas gerais de um novo ideário sanitário (Fleury, 1997).

Segundo esse ponto de vista, as principais idéias-força da reforma sanitária, seriam:

a) o modelo de democracia: a utopia igualitária (universalidade, eqüidade), a garantia da saúde como direito individual ao lado da construção do poder local fortalecido pela gestão social democrática;

b) a proposta de reconceitualização da saúde: reconhecimento da determinação social do processo saúde-doença, trazendo uma perspectiva de atenção integral às necessidades de saúde da população;

c) a crítica às práticas hegemônicas de saúde: proposição de uma nova divisão do trabalho em saúde, incluindo um papel ativo do usuário na construção da saúde.

Além disso, o movimento pela reforma sanitária se estruturou de maneira democrática, diversa, capilar e inclusiva e adotou um estilo de militância coerente com suas proposições.

No processo de luta pela democracia, portanto, a saúde foi um campo em que os diferentes atores sociais comprometidos com a derrota da ditadura contaram com um discurso alternativo ao hegemônico, com formulações $e$ proposições (de saúde, de democracia) e com modos de fazer política compatíveis com a radicalidade da proposta em questão.

É possível que essa seja uma das explicações para que compreendamos a diferença significativa da capacidade de mobilização (e de conquista) do movimento da reforma sanitária quando comparado aos movimentos democráticos no campo da educação, por exemplo.

E provavelmente é essa ainda a explicação para a capacidade que o processo de construção do SUS tem tido de continuar apaixonando, mobilizando $e$ conquistando militantes ao longo dos últimos 15 anos, apesar de todas as dificuldades enfrentadas.

No entanto, o SUS real, apesar de todas as acumulações e avanços, está muito distante da proposta almejada pelo movimento da Reforma Sanitária. Mais grave, as fragilidades atuais do sistema põem em risco sua legitimidade 
política e social, especialmente considerando a situação de permanente disputa em relação à saúde como direito, em relação à concepção de saúde e às maneiras de construí-la.

O modelo tecnoassistencial, a organização da gestão e as maneiras como se faz a política de saúde são todos elementos críticos nesta situação, pois contribuem ou dificultam a mobilização e aglutinação de atores e agentes capazes de contribuir para a indispensável conquista de legitimidade política e social para o SUS.

Por essa razão estes são temas de relevância fundamental para os formuladores das políticas, gestores do SUS em todas esferas e atores implicados com a construção democrática da saúde no país.

\section{A construção do SUS}

O SUS vem conseguindo superar obstáculos importantes em seu processo de implantação. Em tempos de políticas de redução do Estado e de desfinanciamento dos setores sociais, os serviços públicos de saúde foram ampliados, cresceu o número de trabalhadores no setor, a saúde chegou a praticamente todos os municípios do país e, a duras penas, recentemente se conseguiu assegurar recursos mínimos para o setor. Além disso, hoje em dia há um sistema descentralizado, que conta com mecanismos democráticos de funcionamento, que incluem instâncias de pactuação entre os gestores $e$ mecanismos de controle social.

Vale destacar, entretanto, que ao mesmo tempo em que houve avanços na implementação do sistema público, também o subsistema privado, designado constitucionalmente como complementar, avançou em sua organização e na conquista de legitimidade social.

O subsistema privado reforça na sociedade e junto aos profissionais de saúde valores que o SUS procura desconstruir. O direito à saúde é traduzido como direito a consumir serviços médicos, procedimentos e medicamentos, já que existe uma supervalorização da especialização, dos procedimentos e da incorporação de tecnologia a qualquer preço. A oferta de serviços diferenciados de acordo com o poder de compra da pessoa ou do segmento populacional é considerada "normal". Persiste a supervalorização do trabalho do médico, em detrimento do trabalho dos demais profissionais de saúde, e também a centralidade do hospital como instância articuladora do sistema, por ser este o serviço que concentra equipamentos e tecnologia dura (Santos, 2004).

Além disso, em seu processo de constituição, o SUS herdou um conjunto de serviços - hospitais, ambulatórios e unidades básicas - que funcionavam em estreita relação com os serviços privados conveniados por meio da compra de serviços (de internação, laboratoriais e de diagnóstico, por exemplo). Todas essas unidades e serviços operavam com os conceitos hegemônicos de saúde e de organização do trabalho em saúde. $\mathrm{E}$, majoritariamente, assim continuam operando.

As idéias e os valores oriundos do modelo médico-hegemônico são, portanto, predominantes na sociedade. São eles que orientam a formação dos profissionais de saúde e estão presentes na cabeça dos trabalhadores do SUS. Essas idéias e os interesses que elas representam interferem, a todo o 
momento, na possibilidade de consolidação do SUS.

Um exemplo desta interferência: as forças construtoras do SuS lutam por assegurar saúde como direito, acesso universal e eqüidade. Mas não conseguiram transformar a lógica de distribuição dos recursos da saúde, que continuam fortemente orientados à atenção terciária (chamada de alta complexidade), na qual estão concentrados os procedimentos e a tecnologia dura. Em 2004, esse segmento concentrou $73 \%$ dos gastos em saúde, embora tenha sido responsável por um terço dos atendimentos. Ademais, esse segmento é remunerado a preços de mercado, ao contrário de tudo mais no sistema.

Para complicar, atualmente não se pode dizer que continue existindo um movimento sanitário, como um movimento social organizado $e$ militante. Existe, sim, um contingente expressivo de atores mobilizados por tentar construir um sistema de saúde que se aproxime das proposições originais da Reforma Sanitária. Mas não existe mais, como nos tempos préconquista do SUS, o debate intenso, a circulação ampla de propostas, a mobilização contínua em torno de uma disputa política e ideológica feroz.

É no campo da saúde coletiva que se trabalham as idéias herdadas da reforma sanitária, cabendo aos intelectuais e militantes desse campo a formulação de proposições que ajudem o SUS a se aproximar de seus princípios, num jogo complexo, em que existe uma tensão permanente entre saúde como direito do cidadão e saúde como mercadoria.

Parece interessante considerar, como diz Bourdieu (2003), que no campo da saúde, além da lógica de acumulação de bens materiais por meio da compra e venda de equipamentos, insumos, planos de saúde e seguros, está em disputa um mercado de bens simbólicos, que tem seu capital específico, sua forma específica de acumulação, objetos de disputas e lucros diferenciados, que conferem identidade aos diversos campos componentes da sociedade.

Na construção do SUS, portanto, a capacidade de formulação de propostas alternativas para a compreensão da saúde e sua prática é elemento fundamental para a luta por um projeto de sistema, por um projeto de sociedade, para a disputa pela hegemonia setorial.

A hipótese que apresento neste artigo é que é exatamente no campo da política e da formulação das propostas de organização do sistema e das práticas de saúde que temos cotidianamente, e ao longo dos últimos anos, perdido batalhas em defesa da concepção igualitária de direito e de acesso à saúde e do conceito ampliado de saúde.

\section{Os modelos tecnoassistenciais e a disputa pelo conceito e práticas de saúde}

Durante todo o processo de construção do SUS, tem existido uma disputa permanente entre as propostas do campo público e as propostas privatizantes oriundas do setor privado da saúde e das diretrizes internacionais para as políticas sociais (Estado Mínimo, Cesta Básica etc.).

Além disso, no interior do campo da saúde coletiva, longe de haver acordo, tem existido um importante dissenso acerca das estratégias e dos

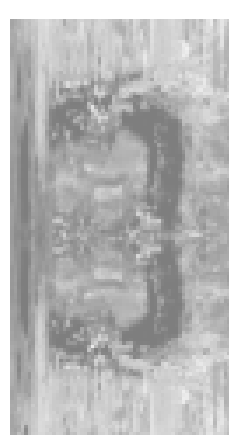


${ }^{2}$ Ver debates sobre Responsabilidade Sanitária (Ministério da Saúde, 2005). conceitos centrais para a construção democrática na saúde.

Durante os primeiros anos de organização do sistema, em suas instâncias de gestão, os principais debates e as polêmicas giraram em torno dos mecanismos de financiamento e de gestão. Havia consenso em relação à necessidade de estabelecer fontes fixas e investimento mínimo indispensável para o financiamento da saúde (luta que acabou desaguando na proposta de emenda constitucional 29 , que estabelece investimentos mínimos em saúde para cada uma das três esferas de gestão). Há desacordos, entretanto, em relação às modalidades de organização do financiamento: críticas do Conasems em relação ao repasse fragmentado de recursos por parte do Ministério da Saúde, muitos deles vinculados a programas e ações específicos, o que reduz a possibilidade de o gestor municipal organizar os serviços de acordo com políticas municipais de saúde e diferentes realidades locais (Santos, 2004).

Havia também dissensos e intensas disputas em relação à efetivação de mecanismos descentralizadores, ao papel de cada esfera na gestão do Sus e à constituição de mecanismos que possibilitassem combinar a autonomia de cada esfera na gestão do sistema com a responsabilidade pelo cumprimento dos compromissos pactuados em torno da oferta dos cuidados indispensáveis à saúde da população.

Embora existam progressos significativos (reconhecimento da gestão plena da atenção básica para todos os municípios, praticamente todos os Estados com gestão plena do sistema), as responsabilidades de cada esfera de governo na saúde continuam em disputa (vide debates sobre o novo Pacto de Gestão, Ministério da Saúde, 2005) e continuam sendo buscados mecanismos mais efetivos para a responsabilização das diferentes esferas de gestão pela superação dos problemas do SUS².

Existe o reconhecimento de que a mudança das práticas de saúde e a reorientação do modelo tecnoassistencial são campos em que o SUS ainda não foi capaz de produzir avanços significativos. No entanto, no âmbito das Comissões Intergestores (Tripartite e Bipartites) e do Conselho Nacional de Saúde tem sido escasso o debate acerca das razões para essa dificuldade ou de alternativas para sua superação. Há, apenas, algum nível de tensionamento, produzido sobretudo por parte dos gestores municipais, para que exista liberdade, principalmente no espaço municipal, para a implementação de diversos arranjos de organização da atenção, respeitados os princípios do SUS.

A partir de 1994, entretanto, o Ministério da Saúde capitaneou um processo de reorganização da atenção básica/atenção primária à saúde por meio do programa/ depois estratégia/depois política de Saúde da Família, que articula elementos das propostas originalmente conhecidas como Sistemas Locais de Saúde/Distrito Sanitário, Programação em Saúde e Promoção à Saúde.

De acordo com o conceito pactuado pela Comissão instituída pela Portaria 676 GM/MS (03/06/2003), composta por representantes do Ministério da Saúde, do Conass e do Conasems, as equipes de Saúde da Família trabalham em um dado território, compreendido não somente como uma área geográfica, mas incluindo toda a complexidade das relações sociais 
e econômicas estabelecidas em seu interior.

A epidemiologia é a principal ferramenta para o planejamento local e para a definição / identificação dos problemas prioritários, que são a base para a articulação das ações e práticas de saúde e a Programação em Saúde é a principal estratégia para organização das práticas de atenção.

Como elementos inovadores em relação à organização das UBS e dos Distritos de Saúde, a Saúde da Família traz o fato de o trabalho não estar centrado na unidade e sim no território, mais precisamente nas famílias. Traz de maneira mais forte a idéia da equipe de saúde, tendo o Agente Comunitário como principal novidade, por sua capacidade de ampliar o diálogo com a população, bem como a compreensão sobre o contexto local, além de fortalecer as possibilidades de vínculo e responsabilização (Souza, 2001).

Vários dos temas polêmicos no campo da saúde coletiva em torno do desenho tecnoassistencial da atenção vêm à tona ao se examinarem os dilemas enfrentados no trabalho das equipes de saúde da família e na organização predominante do sistema de saúde.

Qual o melhor caminho para se construir a integralidade: rede hierarquizada com a atenção básica definida como porta de entrada a priori ou rede como arranjo variável em que se pode entrar por qualquer ponto, ser acolhido e incluído nas ações de acompanhamento, a depender das necessidades de saúde (Cecílio, 2001)? Qual a melhor maneira de assegurar a integralidade: os mecanismos de referência e contrarreferência (eternamente propostos e raramente concretizados) ou a constituição (mais flexível) de equipes de apoio matricial e de mecanismos de educação permanente em saúde de acordo com as necessidades dos trabalhadores da atenção básica (Caldas \& Eller, 2003)?

O SUS - $e$ a Saúde da Família - tem prosseguido com a tentativa de disciplinar a demanda, ao afirmar a atenção básica como porta de entrada do sistema e não se preocupar em criar outros mecanismos de acolhimento $e$ inclusão em outras portas de entrada efetivamente operantes (como são os Pronto-Socorros, por exemplo).

A idéia da hierarquização e a definição de uma porta de entrada que deveria ser capaz de "resolver $80 \%$ dos problemas de saúde" correspondem a um esforço de racionalização, que esbarra exatamente na baixa capacidade das equipes de efetivamente resolverem problemas. Baixa resolubilidade que pode ser explicada de várias maneiras, entre as quais:

- a desarticulação entre a atenção básica $e$ os demais serviços de saúde, já que os sistemas de saúde são organizados por níveis - atenção básica $e$ atenção especializada (dividida em média e alta complexidade) - e não há mecanismos de articulação entre eles, que são operados e financiados segundo lógicas distintas (per capita $x$ procedimentos);

- as importantes limitações da chamada "média complexidade" (que restringem o acesso a procedimentos diagnósticos $e$ ao apoio de especialistas);

- o próprio perfil de formação dos profissionais, particularmente os médicos, que enfrentam profundas dificuldades para dar conta da complexidade dos problemas de saúde mais freqüentes (tanto em seus 
aspectos estritamente clínicos, como em sua relação com as questões sociais como as condições de vida e a violência, por exemplo).

A articulação intersetorial $e$ a promoção à saúde são propostas incorporadas pela Saúde da Família, mas também como atribuição fundamentalmente das equipes da atenção básica. Se, por um lado, multiplicam-se iniciativas criativas nos espaços locais, a potência política que o trabalho intersetorial exige - tanto no controle de recursos como no estabelecimento de prioridades de ação - escapa da governabilidade das equipes e está ausente da agenda da maior parte dos gestores da saúde e dos prefeitos.

Duas outras polêmicas significativas em relação aos modelos tecnoassistenciais dizem respeito às tecnologias mais adequadas para organizar as práticas de saúde e às possibilidades de inovação das práticas de saúde no âmbito concreto da atuação das equipes e dos trabalhadores da saúde.

Segundo a lógica da Programação em Saúde, adotada como referencial pela Saúde da Família, haveria uma polarização entre epidemiologia e clínica: uma centrada na saúde e a outra na doença, uma operando com a determinação social do processo saúde-doença $e$ a outra com a concepção biológica da saúde (Merhy et al, 2003). A programação em saúde levaria os trabalhadores a adotarem práticas orientadas pela epidemiologia e pelo referencial da saúde e, portanto, mais potentes que as ensejadas pela clínica e pelo referencial das doenças (Schraiber, 1990). Os condicionamentos políticos, materiais e ideológicos tornariam escassas as possibilidades de renovação da clínica, levando os profissionais, atuando livremente, a reproduzir as práticas hegemônicas de saúde (Schraiber \& Machado, 1997).

Segundo o movimento pela Defesa da Vida (Campos, 1992; Cecílio, 2001; Merhy, 1997) a epidemiologia seria uma ferramenta útil para dimensionar e priorizar problemas, mas não poderia substituir a clínica, que é a tecnologia de que dispomos para o cuidado individual. A clínica deveria ser ampliada, enriquecida por novos referenciais, pelo resgate da dimensão cuidadora e pela produção de tecnologias leves, relacionais, de modo a ampliar a capacidade dos trabalhadores de lidar com a subjetividade e com as necessidades de saúde dos usuários. Ao invés de restringir a liberdade e a autonomia dos trabalhadores da saúde por meio da programação, a aposta seria investir ao máximo nesse espaço, ampliando mecanismos $e$ oportunidades para comprometê-lo com a atenção às necessidades dos usuários, com a produção de um cuidado integral à saúde (Merhy, 2003).

É possível constatar múltiplas tensões na organização do trabalho na Saúde da Família. Apesar das práticas com o coletivo, com as famílias, nas casas, nos locais de trabalho e convivência serem teoricamente uma atribuição do conjunto da equipe, elas são assumidas principalmente pelos agentes comunitários, seguidos pelos profissionais da enfermagem. A carga de atenção por meio das consultas clínicas é extremamente pesada e ocupa grande parte da agenda dos médicos.

Os programas efetivamente produzem um certo ordenamento das práticas de saúde, ao tempo que criam uma carga grande de "procedimentos obrigatórios". Ou seja, as necessidades de saúde definidas tecnicamente por 
meio da epidemiologia e as práticas estabelecidas por meio da Programação em Saúde definem e ao mesmo tempo limitam o repertório de ação dos trabalhadores, pois desconsideram as singularidades e oferecem poucas tecnologias para o cuidado e para lidar com os aspectos subjetivos envolvidos no processo de viver e adoecer. Sem novas tecnologias, o cuidado clínico ou fica restrito ou reproduz o hegemônico. Além disso, as equipes enfrentam muitas dificuldades para lidar com a demanda espontânea $e$ a atenção a elas quase sempre se conforma no esquema queixa-conduta.

A contraposição entre epidemiologia e clínica está por trás da opção por investir na atenção básica para reorganizar as práticas de saúde. A atenção básica seria o mundo das práticas coletivas, portanto mais favorável às inovações programáticas e paradigmáticas, e os demais segmentos do sistema seriam o mundo da clínica, subjugado por conceitos e práticas hegemônicas de saúde.

Em conseqüência, não se propuseram políticas ou iniciativas significativas para reconfigurar as práticas de saúde na atenção especializada e nos hospitais (no máximo trabalhou-se pela humanização desses serviços, particularmente dos hospitais) que, portanto, continuam efetivamente operando na lógica hegemônica.

Na prática, então, não se construíram os meios para haver um diálogo entre a atenção básica e os serviços especializados e hospitalares. São dois mundos supostamente articulados, mas operando com lógicas distintas. E, nesse enfrentamento, a atenção básica sai perdendo, pois socialmente ela é o local das "práticas simplificadas", da "medicina de pobre para pobres", sempre "culpabilizado" por sua ineficiência e desqualificação.

Ou seja, ao não enfrentar a disputa ideológica em todos os campos da saúde e ao não buscar inovar a prática clínica, o modelo tecnoassistencial implementado de maneira predominante no SUS vem propiciando a reafirmação de conceitos e práticas hegemônicas em saúde e condenando a um gueto o espaço da atenção básica, que é onde se espera que esteja havendo a produção de práticas de saúde inovadoras.

As equipes de Saúde da Família que efetivamente se comprometem com a construção do SUS e se responsabilizam pelo cuidado à saúde dos usuários ( $e$ são muitas, em todo o território nacional) angustiam-se diante de seu isolamento e da falta de governabilidade para enfrentar problemas decisivos para a produção da saúde nos diferentes contextos (Matumoto, Fortuna et al, 2005).

Sem romper o isolamento, sem a produção de novas tecnologias para o cuidado em saúde e sem colocar a construção de linhas de cuidado na agenda da gestão do sistema (rompendo com o isolamento da atenção básica e com a hierarquização burocrática), dificilmente será possível produzir atenção à saúde de qualidade, atendendo às expectativas dos usuários todos esses elementos indispensáveis para a consolidação política do Sus.

Mas isso não é tudo. A gestão do sistema e o modo de fazer política de saúde são também elementos fundamentais nesse processo.

A gestão do sus e os modos de fazer política de saúde Uma outra polêmica importante no campo da saúde coletiva gira em torno

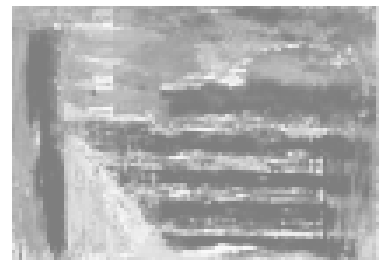


das maneiras de fazer cumprir os compromissos democráticos e democratizantes na construção do SUS, um elemento importante da "alma" do movimento pela Reforma Sanitária.

Há vários âmbitos para se pensar a democratização do sistema: o dos conselhos e das conferências - mecanismos de participação representativa de prestadores, trabalhadores e usuários na gestão; o das relações entre os gestores das três esferas (bipartites e tripartite) e o da participação direta de trabalhadores e usuários no cotidiano dos serviços de saúde.

O movimento pela reforma sanitária produziu muitos conceitos $e$ propostas a partir de experimentações e da mobilização ativa de diferentes atores sociais. Assim como a descentralização dos serviços de saúde iniciou-se antes da constituição do SUS, por meio do SUDS (Sistema Unificado $e$ Descentralizado de Saúde) e das AIS (Ações Integradas de Saúde), os mecanismos de participação social foram sendo gestados antes de 1988, por meio das Comissões Interinstitucionais de Saúde (CIS). Foi a partir dessa experiência que foram concebidos os Conselhos de Saúde, legalmente instituídos pela Lei 8142 .

Esses Conselhos (locais, municipais, estaduais e o nacional) existem e funcionam e, apesar de todas as suas limitações, constituem um dos mecanismos mais democráticos de controle das atividades públicas existentes no país. Suas limitações têm a ver com o grau de organização da sociedade civil, os problemas intrínsecos dos mecanismos representativos de participação e as práticas políticas dominantes no país, entre outros elementos (Bogus, 1998).

Apesar disso, os conselhos e as conferências de saúde são ainda um espaço de militância e por meio deles milhares de brasileiros participam de debates $e$ interferem de algum modo nos destinos do sistema de saúde. Mas falta avançar para serem mecanismos efetivos de gestão democrática $e$ participativa, como se pretendia com o movimento da reforma sanitária (Carvalho, 1997).

No que diz respeito às relações entre os gestores das três esferas do SUS, também houve avanços e há mecanismos de negociação que são inimagináveis para outros setores da sociedade brasileira. As Comissões Intergestores, tanto as estaduais como a nacional, configuram-se como espaço de disputa e negociação, constituindo-se como os principais fóruns de pactuação das políticas de saúde no país. São esses mecanismos de pactuação que tornam possível o funcionamento descentralizado e articulado do SUS, bem como a existência de políticas nacionais de saúde (ao contrário do que acontece na Educação, em que os Conselhos Estaduais de Educação têm completa autonomia em relação à esfera federal).

No entanto, a "autonomia de gestão" dos entes federados e as atribuições de cada esfera de gestão do SUS continuam sendo objeto de intensa disputa. A descentralização por meio da municipalização ocorreu, é fato. Saúde é responsabilidade de cada gestor municipal deste país, já que os municípios efetivamente são os principais prestadores de serviços de saúde $e$ os maiores empregadores de trabalhadores de saúde (Ministério da Saúde, 2005).

No entanto, é restrita sua autonomia para a definição das políticas e das 
prioridades de ação, especialmente pelo fato de, sobretudo o Ministério da Saúde, utilizar intensivamente mecanismos financeiros para "induzir" a adoção e implementação de políticas. Como a esfera federal é responsável por aproximadamente $50 \%$ do financiamento da saúde, seu poder de pressão/ "indução" é muito significativo.

A esfera estadual deixou de ter um papel significativo na prestação dos serviços, sobretudo na atenção básica, embora ainda cumpra papel significativo na prestação de serviços especializados em âmbito regional $e$ estadual. Sem papel importante na prestação de serviços, as secretarias estaduais de modo geral ainda não se qualificaram para um papel político de formulação ou de apoio técnico aos municípios (Barata, 2004; Martins Jr., 2004). As SES disputam, particularmente com os grandes municípios, a gestão de hospitais e equipamentos especializados de atuação regional $e$ também o controle sobre a distribuição dos recursos transferidos pelo Ministério da Saúde, sob o lema de assegurar a eqüidade (Barata et al., 2004).

Existe também um desequilíbrio importante na capacidade de ação articulada entre secretários estaduais e secretários municipais de saúde. O Conselho Nacional de Secretários Estaduais de Saúde (CONASS) articula apenas 27 secretários e desenvolveu mecanismos potentes de pactuação entre pares (Assembléias, Câmaras Técnicas etc.), além de contar com um corpo de assessores praticamente profissionalizado ${ }^{3}$.

Já o Conselho Nacional de Secretários Municipais de Saúde (CONASEMS) conta com um corpo de assessores mais restrito (Conasems, 2005) e enfrenta dificuldades para uma articulação mais ágil e orgânica. São mais de 5600 municípios no país, a grande maioria (73\%) com menos de vinte mil habitantes, com realidades, governabilidade e problemas muito distintos entre si. Desde 2003, existe a preocupação explícita com a necessidade de formular políticas específicas para municípios de diferentes portes nas diferentes regiões do país (Conasems, 2003).

Há dificuldades significativas de comunicação e articulação, implicando limitações para a participação efetiva dos gestores municipais nas múltiplas comissões tripartites de trabalho instituídas pelas diferentes áreas do Ministério da Saúde (por essa razão, a partir de março de 2004, o Conasems só se compromete a enviar representantes "com poder de deliberação" às reuniões das Comissões Técnicas Oficiais da Comissão Intergestores Tripartite) (Ministério da Saúde, 2004).

Além disso, os braços estaduais do CONASEMS - os COSEMS - também enfrentam muitas dificuldades. Falta de estrutura, de recursos para operar, de quadros de apoio e, em muitos casos, um importante grau de dependência em relação às Secretarias Estaduais de Saúde.

A coesão e a capacidade de sustentar posições e conduzir enfrentamentos dos dois Conselhos Nacionais na Comissão Intergestores Tripartite são, portanto, muito diversas. E justamente a voz e os interesses dos municípios, os mais próximos da realidade e dos atores locais, é que ficam em relativa desvantagem.

Em função de todos esses elementos, apesar dos avanços inegáveis e da efetiva pactuação existente no SUS, no campo da formulação das políticas de
${ }^{3}$ Ver, por exemplo, a produção de documentos técnicos preparatórios aos debates da Tripartite, disponíveis no sítio virtual do CONASS (www.conass.org.br). 


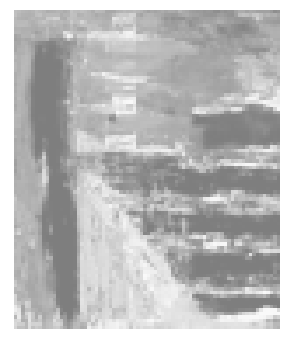

saúde existe um predomínio importante da esfera federal e, portanto, de políticas nacionais, que tendem a prescrever uma uniformização da organização da atenção à saúde em todo o território nacional.

A Saúde da Família é um bom exemplo desse modo de fazer política. Em função dos mecanismos financeiros de "indução", ela é o modo predominante de organização formal da atenção básica no país e suas diretrizes são muito pouco flexíveis para possibilitar, por um lado, o exercício de liberdade do gestor municipal para configurar seu sistema municipal, e, por outro, para contemplar a diversidade de realidades locais (Caldas \& Eller, 2003; Marques \& Mendes, 2003).

E aí aflora uma contradição, pois, pela força da indução financeira, todos "obedecem", mas, ao mesmo tempo, desobedecem, pois há tantas "saúdes da família" quantas equipes de saúde da família existem no país. Para compensar, então, são instituídos mecanismos de controle $e$ acompanhamento, exercidos geralmente pelas secretarias estaduais de saúde por meio de coordenações de programa (Barata et al., 2004).

São múltiplas as dificuldades que essa lógica da organização do sistema impõe ao processo de trabalho. Um bom exemplo é o do planejamento. De acordo com a própria Saúde da Família, o planejamento local seria uma das atividades fundamentais para organizar o trabalho das equipes.

O planejamento, então, deveria ser local, mas na Atenção Básica as metas são pactuadas nacionalmente, num calendário definido centralmente, que praticamente impede a participação ativa e efetiva das equipes e dos espaços locais (Ministério da Saúde, 2001). Além disso, apesar de coletarem os dados $e$ alimentarem os sistemas de informação, muitas das equipes da atenção básica não dispõem da informação processada para ser utilizada no seu espaço de ação.

Existem, portanto, contradições entre os princípios do SUS e a maneira como os próprios atores constitutivos do sistema operam. Essas contradições, esperadas, se não tratadas, terminam por legitimar as velhas idéias e valores e, portanto, precisam ser debatidas e superadas.

É assim também no que diz respeito à articulação das políticas e à construção da integralidade. Tradicionalmente o Ministério e as Secretarias de Saúde trabalham com as políticas de saúde de modo fragmentado: gestão separada da atenção, atenção separada da vigilância e cada uma delas dividida em tantas áreas técnicas quantos sejam os campos de saber especializado (Santos, 2004).

Cada área técnica parte do máximo de conhecimentos acumulados em seu campo e dos princípios políticos considerados mais avançados para examinar os problemas de saúde do país. A partir dessas referências, são propostos os programas de ação, e para a implementação de cada programa, propõe-se uma linha de capacitações.

Como a maior parte dos programas estão dirigidos à atenção básica, as equipes de saúde da família são a "via final comum" ou o "braço efetor" de praticamente todas as "políticas setoriais" produzidas no Ministério da Saúde.

Os trabalhadores são considerados "caixas vazias", que devem ser orientadas pelas normas. Ou seja, por meio dos programas - que estabelecem 
e padronizam ações- e das capacitações e dos manuais - que levam as orientações programáticas aos trabalhadores - espera-se normalizar $e$ ordenar o seu trabalho, no caso do SUS, em direção a práticas inovadoras de saúde (Campos, 1997).

De modo geral, esses processos se reproduzem nas esferas estadual $e$ municipal e há escassas oportunidades de participação direta dos trabalhadores e usuários na formulação das políticas e na construção das práticas.

Ora, a centralização dos processos políticos e a fragmentação do trabalho levam os profissionais à loucura ou ao desinteresse, à alienação e à desresponsabilização em relação aos resultados finais. Se no campo da produção em geral essa maneira de operar a organização do trabalho traz problemas, em saúde a coisa é ainda mais complicada e os resultados, medíocres, e, no caso do SUS, mais grave ainda, pois é impossível transformar práticas com esse tipo de condução política e técnica (Campos, 1997; Merhy, 2002).

No campo da democratização, portanto, o SUS real também fica devendo aos princípios e proposições do movimento pela Reforma Sanitária. E, mais grave, esse assunto não ocupa um lugar central na agenda política de construção do sistema.

A política de educação permanente em saúde instituída durante os primeiros dois anos e meio do governo Lula procurou de algum modo endereçar esses problemas, mas nunca foi debatida nesses termos nas instâncias do sistema e nem mesmo no próprio Ministério da Saúde, pois ainda predomina uma visão instrumental da construção dos modelos tecnoassistenciais (centrada nas normas e nos mecanismos de financiamento) e não se atribui à política de educação um papel estruturante no sistema (é considerada uma política meio).

Os Pólos de Educação Permanente em Saúde, a formação de facilitadores de educação permanente em saúde, os municípios colaboradores da educação permanente em saúde, a Articulação Nacional de Movimentos e Práticas de Educação de Educação Popular em Saúde (ANEPS), o Fórum Nacional de Ensino das Profissões da Saúde (FNEPAS), a formação de ativadores de processos de mudanças na graduação e as Vivências e Estágios no SUS (VER-SUS) foram todos dispositivos e estratégias para criar novos espaços democráticos de debate e construção descentralizadas de políticas de saúde, que possibilitavam a participação ativa de novos atores (estudantes $e$ professores da área da saúde e os movimentos sociais) e ampliação das oportunidades de gestores municipais e trabalhadores do SUS participarem ativa e decisivamente desse processo.

Os novos espaços criados, particularmente os Pólos, sofreram com a dificuldade dos vários atores de construírem mecanismos de convivência, comunicação e pactuação e necessitam de ajustes para operar de maneira mais efetiva. Mas será que foi diferente nos momentos iniciais das Comissões Interinstitucionais de Saúde? Será que a solução face ao despreparo dos diferentes atores diante do desafio da formulação de políticas é a abolição dos espaços democráticos ao invés do desenvolvimento de estratégias específicas para o seu fortalecimento? 
A partir de julho de 2005, houve a troca da equipe do Ministério da Saúde e a revisão das políticas e estratégias implementadas anteriormente. Valeria a pena analisar e debater técnica e politicamente a experiência vivida, especialmente considerando os diferentes aspectos inovadores implementados.

\section{O trabalho em saúde}

Para começar, o trabalho em saúde não é completamente controlável, pois se baseia em uma relação entre pessoas, em todas as fases de sua realização e, portanto, sempre está sujeito aos desígnios do trabalhador em seu espaço autônomo, privado, de concretização da prática.

Muito longe de ser uma "caixa vazia", cada trabalhador e cada usuário tem idéias, valores e concepções acerca de saúde, do trabalho em saúde e de como ele deveria ser realizado. E todos os trabalhadores fazem uso de seus pequenos espaços de autonomia para agir como lhes parece correto, de acordo com seus valores e/ou interesses (Helman, 2003).

Os serviços de saúde, então, são palco da ação de um time de atores, que têm intencionalidade em suas ações e que disputam o sentido geral do trabalho. Atuam fazendo uma mistura, nem sempre evidente, entre seus territórios privados de ação e o processo público de trabalho. O cotidiano, portanto, tem duas faces: a das normas e papéis institucionais e a das práticas privadas de cada trabalhador (Merhy, 2002).

Os gestores (federais, estaduais e municipais) do sus cumprem um papel decisivo na conformação das práticas de saúde por meio das políticas, dos mecanismos de financiamento etc., mas não governam sozinhos. Apesar de haver uma direção - os gestores - a quem formalmente cabe governar, na verdade todos governam - os trabalhadores e os usuários. Carlos Matus diz que todos são agentes da organização $(\mathrm{g})$ e alguns estão em posição de "alta direção" (G). Então, a verdadeira organização é definida pelo conjunto de ações governamentais que todos fazem no dia-a-dia. Ou seja, planeja (governa) quem faz (Matus, 1996).

Quer dizer, então, que todo ator em situação de governo encontra diante de si outros atores que também governam e disputam com ele a direcionalidade da ação, utilizando para isso os recursos de que dispõem. Claro que os atores em situação de governo dispõem, em princípio, de maior controle sobre recursos, mas eles precisam saber governar (e necessitam para isso de uma dada caixa de ferramentas, que compõe sua capacidade de governar). Quando um ator "joga bem”, pode ampliar sua governabilidade. Esse é um elemento fundamental para a gestão das organizações de saúde e para os que pretendem favorecer a transformação das práticas de saúde.

Existem, então, pelo menos três campos de tensão que operam nas organizações de saúde (Merhy, 2002):

- O território das práticas de saúde é um espaço de múltiplas disputas e de constituição de políticas desenhado a partir da ação de distintos atores, que, dependendo de seus interesses e capacidade de agir, aliam-se ou confrontam-se na tentativa de afirmar uma certa conformação da saúde que faça sentido. A única maneira de enfrentar esse jogo de modo a fazer valer os interesses dos usuários é por meio do controle social e da pactuação 
política.

- A produção de atos de saúde é um terreno do trabalho vivo (isto é, um terreno no qual predominam as tecnologias leves - relacionais - em detrimento das tecnologias duras - equipamentos e saberes estruturados). Isso acontece porque a produção de atos de saúde opera sempre com altos graus de incerteza e com grau não desprezível de autonomia dos trabalhadores. É exatamente essa característica que abre grandes possibilidades para estratégias que possibilitem a construção de novos valores, compreensões e relações, pois há espaço para a invenção.

- O terreno das organizações de saúde, por ser um espaço de intervenção de diferentes atores a partir de suas capacidades de auto-governo, que disputam a orientação do dia-a-dia com as normas e regras instituídas, está sempre tensionado pela polaridade entre autonomia e controle. Este também é um espaço de possibilidades para a construção de estratégias que levem os trabalhadores a utilizar seu espaço privado de ação em favor do interesse público (dos usuários).

Esses três campos de tensão são lugares estratégicos para qualquer intervenção com o objetivo de aumentar a governabilidade do gestor ou para definir as possibilidades de implementação de um dado desenho organizativo da atenção.

A intervenção pode estar orientada a aumentar a governabilidade do gestor por meio da ampliação dos controles, impactando os exercícios privados dos profissionais (restringindo-a, por exemplo, por meio do controle de custos ou por meio da instituição de programas), atuando sobre as disputas que ocorrem cotidianamente e buscando impor controle sobre elas e, finalmente, impondo os interesses particulares de alguns como sendo os interesses de todos.

Mas eles podem ser espaços estratégicos para disparar novos processos de produção da saúde, novos desafios às práticas e conceitos dominantes $e$ novas relações de poder. A grande possibilidade de quebra da lógica predominante na saúde é sua desconstrução no espaço da micropolítica, da organização do trabalho e das práticas (Merhy, 2002).

A modo de encerramento, abrindo novos desafios É fundamental construir um olhar analisador sobre as "fragilidades" do suS. As idéias, propostas e políticas implementadas na gestão e organização da atenção de maneira predominante no SUS não têm produzido alternativas políticas e técnicas suficientes para operar as transformações do conceito $e$ das práticas de saúde, bem como a democratização que o projeto da Reforma Sanitária propõe e supõe.

O SUS, que é uma política, um projeto e várias outras coisas ao mesmo tempo, pede atores sociais para ser produzido, sustentado e recriado. No entanto, a construção do sistema vem sendo operada numa realidade em que, de fato, não há atores totalmente consolidados para cumprir estas tarefas (lembremos da realidade do controle social, da configuração de gestores estaduais e municipais, da não participação direta e cotidiana de trabalhadores e usuários na construção das políticas de saúde).

Em função de tudo isso, o SUS não é hegemônico. Na prática, é frágil e 
está em plena construção. Não há indícios claros de que será possível implantá-lo em sua profundidade básica, pois para tanto dependemos, decisivamente, da fabricação de atores para cumprir esses papéis em novos espaços de encontro e produção das práticas e políticas de saúde.

Segundo o postulado da coerência de Testa, um movimento (ou projeto) tem que adotar meios e organizações coerentes com o conteúdo de suas propostas (Testa, 1995). Desse modo, a consolidação do SuS requer coerência com os princípios do movimento da Reforma Sanitária, tanto no que diz respeito à consciência sanitária, como aos modos de fazer política $e$ de organizar o processo de trabalho.

Para consolidar a saúde como direito democrático, do cidadão, (e não como objeto de consumo), para trabalhar com um conceito ampliado de saúde, articular-se com outras políticas para enfrentar os determinantes sociais da saúde e da doença e para satisfazer as necessidades de cuidado expressas pelos usuários, será necessário ousadia no campo da política (como na época da VIII e da Constituinte).

A disputa pelo capital simbólico da saúde (Bourdieu, 2003) requer a possibilidade do debate político intenso e a militância por um projeto de saúde. A necessária coerência dos meios com os princípios implica ampliação da descentralização, o respeito à autonomia das diferentes esferas de gestão; implica ampliação da liberdade para a construção de novos arranjos tecnoassistenciais (regionais e locais). Implica, finalmente, na construção de estratégias políticas inovadoras para ampliar o contato entre os usuários e os trabalhadores de saúde na reorganização do processo de trabalho e na instituição da gestão democrática.

Muitos municípios brasileiros vêm desenvolvendo experiências relevantes no campo da reorganização da atenção, da educação permanente, da democratização da gestão, da instituição de linhas de cuidado, construindo redes mais flexíveis, espaços de gestão participativa, coletivos produtores de cuidado (Merhy et al, 2003: Franco et al., 2004: Santos, 2004).

Num contexto político complexo como o atual, em que a decepção e a perda de confiança nas instituições e na política ganham força, o SUS - sua consolidação - pode ser um espaço de resgate da cidadania. Nesta perspectiva, alguns de nossos desafios, provavelmente, alocam-se na necessidade de recuperar a disposição e os meios para uma ampla participação na construção das políticas e das práticas de saúde; bem como na abertura sistemática de novos espaços de experimentação e a ampliação da produção de conhecimento a respeito das estratégias de gestão democrática, do processo de trabalho em saúde, das diferentes possibilidades de construção da rede de atenção à saúde e que se produzem novas tecnologias de cuidado orientados às necessidades de saúde dos usuários.

A construção dos espaços democráticos e dos atores necessários à construção do SUS não está plenamente contida na institucionalidade já produzida e consolidada no sistema. Novos arranjos políticos, de gestão e de participação são, portanto, indispensáveis (Merhy, 2005).

Não são poucas as questões postas a amplos segmentos técnicos, políticos e acadêmicos e que parecem indispensáveis para a consolidação do sus que queremos: usuário-centrado, democrático e em defesa da vida. 
FEUERWERKER, L. M.

\section{Referências}

AROUCA, S. A reforma sanitária brasileira. Tema, Radis, n.11, p.2-4, 1998.

Bogus, C.M. Participação popular em saúde: formação política e desenvolvimento. São Paulo: Annablume/FAPESP, 1998.

BARATA, L. R. B.; TANAKA, O. Y.; VILAÇA, J. D. V. O papel do gestor estadual no Sistema Único de Saúde. Conselho Nacional de Secretários de Saúde. Convergências e Divergências sobre Gestão e Regionalização do SUS. Brasília: CONASS, 2004. (CONASS Documenta; 6). Disponível em: <http://www.conass.org.br/admin/arquivos/documenta6.pdf>. Acesso em: 7 ago. 2005.

BOURDIEU, P. A economia das trocas simbólicas. São Paulo: Perspectiva, 2003.

CALDAS, E. L.; ELLER, E. P. Programa Paidéia de Saúde da Família. Campinas: Prefeitura Municipal, 2003.

CAMPOS, G. W. S. Subjetividade e administração de pessoal: considerações sobre modos de gerenciar trabalho em equipes de saúde. In: MERHY, E. E.; ONOCKO, R. (Org.) Agir em saúde: um desafio para o público. São Paulo: Hucitec, 1997. p.229-66.

CAMPOS, G. W. S. A reforma da reforma: repensando a saúde. São Paulo: Hucitec, 1992.

CAMPOS, G. W. S. A saúde pública e a defesa da vida. São Paulo: Hucitec, 1991.

CARVALHO, A. I. Conselhos de saúde, responsabilidade pública e cidadania: a reforma sanitária como reforma do Estado. In: FLEURY, S. (Org.) Saúde e Democracia: a luta do Cebes. São Paulo: Lemos Editorial, 1997. p.93-112.

CECÍLIO, L. C. As necessidades de saúde como conceito estruturante na luta pela integralidade e equidade na atenção em saúde. In: PINHEIRO, R.; MATTOS, R. (Org.) Os sentidos da integralidade. Rio de Janeiro: IMS- UERJ - Abraco, 2001. p.113-26

CONASEMS. Carta de Belo Horizonte. Disponível em: <www.conasems.org.br/congressos. Brasília, 2003. Acesso em: 7 nov. 2005.

CONASEMS. Apresentação sobre nova estrutura do escritório do Conasems em Brasília. Brasília, 2005. Disponível em: <http://www.conasems.org.br/notícias> 12/8/2005. Conheça a nova estrutura do escritório do Conasems. Acesso em: 7 nov. 2005.

FRANCO, T. B.; PERES, M. A.; FOSCHIERA, M.; PANIZZI, M. Acolher Chapecó: uma experiência de mudança do modelo assistencial com base no processo de trabalho. São Paulo: Hucitec, 2004.

FLEURY, S. A questão democrática na saúde. In: FLEURY, S. (Org.) Saúde e democracia: a luta do Cebes. São Paulo: Lemos Editorial, 1997. p.26-42.

HELMAN, C. Cultura, saúde e doença. Porto Alegre: Artmed, 2003.

MARQUES, R. M.; MENDES, A. Atenção Básica e Programa de Saúde da Família: novos rumos para a política de saúde e de financiamento? Ciênc. Saúde Col., v.8, n.2, p.403-15, 2003.

MARTINS JUNIOR, F. Análise do processo de implantação do SUS no Brasil. In: Progestores: convergências e divergências sobre a gestão e a regionalização do SUS. Brasília: CONASS, 2004.

MATUMOTO, S.; FORTUNA, C.; MISHIMA, S.; PEREIRA, M. J. B; DOMINGOS, N. A. M. Supervisão de equipes no Programa de Saúde da Família: reflexões acerca do desafio da produção de cuidados. Interface - Comunic., Saúde, Educ., v.9, n.16, p.9-24, 2005.

MATUS, C. Política, planificação e governo. Brasília: IPEA, 1996.

MENDES, E. V. O SUS que temos e o SUS que queremos. Conselho Nacional de Secretários de Saúde. Convergências e Divergências sobre Gestão e Regionalização do SUS, Brasília: CONASS, 
2004. Disponível em: <http://www.conass.org.br/admin/arquivos/documenta6.pdf>. Acesso em: 7 ago. 2005.

MERHY, E. E. Em busca do tempo perdido: a micropolítica do trabalho vivo em saúde. In: MERHY, E. E.; ONOCKO, R. (Org.) Agir em saúde: um desafio para o público. São Paulo: Hucitec, 1997. p.71-112.

MERHY, E. E. Saúde: a cartografia do trabalho vivo em ato. São Paulo: Hucitec, 2002.

MERHY, E.E. Engravidando as palavras: o caso da integralidade. In: PINHEIRO, R.; MATTOS, R. (Org.)

Construção social da demanda. Rio de Janeiro: IMS-UERJ/ Abrasco, 2005. p.195-206.

MERHY, E.E.,MAGALHÃES JR.; H. M.; RIMOLI, J. O trabalho em saúde: olhando e experenciando o SUS no cotidiano. São Paulo: Hucitec, 2003.

MINISTÉRIO DA SAÚDE. Relatório da CIT 2004. Disponível e,: <www.saude.gov.br>. Brasília, 2004. Acesso em: 7 nov. 2005.

MINISTÉRIO DA SAÚDE. Pacto dos indicadores da Atenção Básica. Informe da Atenção Básica (Brasília), n.9, 2001. Disponível em: <http://dtr2004.saude.gov.br/dab/documentos/informes/ psfinfo9.pdf>. Acesso em: 7 nov. 2005.

MINISTÉRIO DA SAÚDE. Comissão Intergestora Tripartite. Documento base para o processo de trabalho de discussão e elaboração de propostas para a construção do pacto de gestão. Brasília, 2005. Disponível em: <http://cedoc.ensp.fiocruz.br/descentralizar/anexos/ documento\%20base\%20para\%20a\%20construção\%20do\%20pacto\%20de\%20gestão.pdf>. Acesso em: 7 ago. 2005.

PAIM, J. S. A reorganização das práticas de saúde em distritos sanitários. In: MENDES, E. V. (Org.) Distrito Sanitário: o processo social de mudança das práticas sanitárias do Sistema Único de Saúde. São Paulo/Rio de Janeiro: Hucitec/ Abrasco, 1993. p.187-220.

PAIM, J. S. Bases conceituais da reforma sanitária brasileira. In: FLEURY, S. (Org.) Saúde e democracia: a luta do Cebes. São Paulo: Lemos Editorial, 1997. p.11-24.

SCHRAIBER, L. B. (Org) Programação em saúde hoje. São Paulo: Hucitec, 1990.

SCHRAIBER, L.; MACHADO, M. H. Trabalhadores de saúde: uma nova agenda de estudos sobre recursos humanos em saúde no Brasil. In: FLEURY, S. (Org.) Saúde e democracia: a luta do Cebes. São Paulo: Lemos Editorial, 1997. p.281-98.

SANTOS, N. R. Ética social e os rumos do SUS. Conassems, 2004. Disponível em: <http:// www.conasems.org.br/mostraPagina.asp?codServico=1327\&codPagina=1334\#>. Acesso em: 7 ago. 2005.

SOUSA, M. F. A Cor-Agem do PSF. São Paulo: Hucitec, 2001.

TESTA, M. Pensamento estratégico e lógica de programação: o caso da saúde. São Paulo/Rio de Janeiro: Hucitec/ Abrasco, 1995.

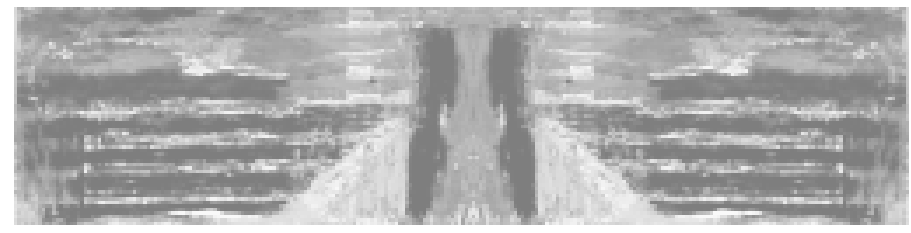




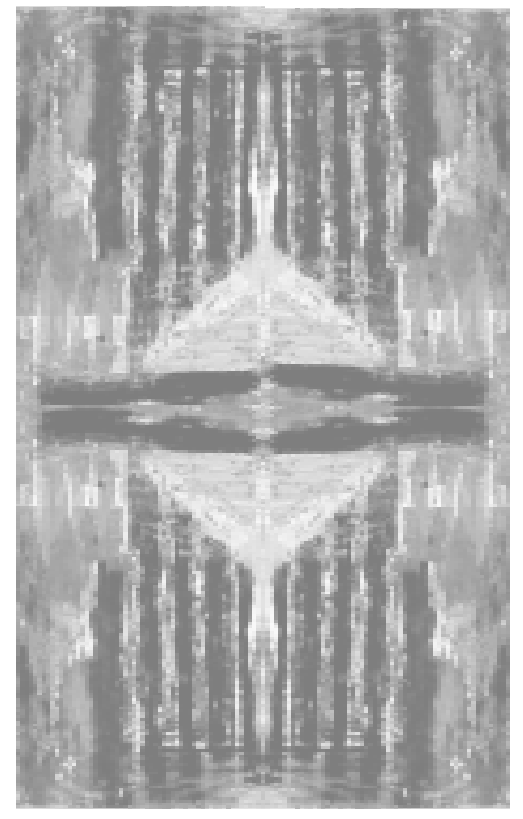

FEUERWERKER, L. M. Modelos tecnoasistenciales, gestión y organización del trabajo en salud: nada es indiferente en el proceso de lucha para la consolidación del suS. Interface - Comunic., Saúde, Educ., v.9, n.18, p.489-506, set/dez 2005.

El artículo propone una reflexión crítica respecto al actual momento de desarrollo de la construcción del Sistema único de Salud, tomando como referencia los principios propuestos por el Movimiento de la Reforma Sanitaria Brasileña, particularmente en lo que respecta a los compromisos democráticos con relación al derecho a la salud y a la construcción del sistema y de sus políticas, y a la transformación de las prácticas de salud $y$ al modelo tecnoasistencial. Son analizadas las maneras predominantes de organizar la atención a la salud, de producir políticas de salud y de enfrentar los retos impuestos por el proceso de trabajo en salud. Se defiende la idea de que es necesaria una radicalización democrática, que posibilite la participación activa y efectiva de los gestores municipales de salud, de los trabajadores y usuarios en la construcción del SUS, como condición indispensable para su consolidación y el derecho ciudadano a la salud.

PALABRAS CLAVE: salud como derecho ciudadano. modelo tecnoasistencial. democratización de la gestión. formulación de las políticas de salud. micropolítica del trabajo en salud. 